\section{InGaP/InGaAs PHEMT with high IP3 for low noise applications}

Y.C. Lin, E.Y. Chang, G.J. Chen, H.M. Lee, G.W. Huang, D. Biswas and C.-Y. Chang

\begin{abstract}
A low noise $\mathrm{InGaP} / \mathrm{InGaAs}$ pseudomorphic high-electron-mobility transistor (PHEMT) with high IP3 was developed. The device utilises InGaP as the Schottky layer to achieve a low noise figure and uses $\mathrm{AlGaAs}$ as the spacer to reform the electron mobility and contains dual delta doped layers to improve the device linearity.
\end{abstract}

Introduction: An InGaP/InGaAs based pseudomorphic high-electronmobility transistor (PHEMT) with AlGaAs spacer for low noise and high linearity application is developed. The device structure is as shown in Fig. 1. It uses high doping concentration $n^{+}$-GaAs as cap layer to form good ohmic contact for the drain and source electrodes. The InGaP layer is used as the Schottky layer. The use of InGaP instead of AlGaAs as the Schottky layer for the PHEMT has the following advantages. Foremost, InGaP has higher energy bandgap that can reduce the gate leakage current. Additionally, InGaP does not form a deep-complex (DX) centre at the desired doping level. Finally, high etch selectivity between InGaP and GaAs can be achieved, which improves the gate recess uniformity [1]. In this Letter, we use AlGaAs as the spacer layer above and below the InGaAs channel layer to increase the electron mobility, and high electron mobility of $6410 \mathrm{~cm}^{2} / \mathrm{Vs}$ in the 2DEG channel region was achieved. This is believed to be highest electron mobility formed in the $\mathrm{InGaP} / \mathrm{InGaAs}$ PHEMT. Two delta-doped layers are used above and below the quantum well region to improve the transconductance flatness of the device $[2,3]$. Finally, AlGaAs/GaAs superlattice was used to reduce the leakage current from the substrate.

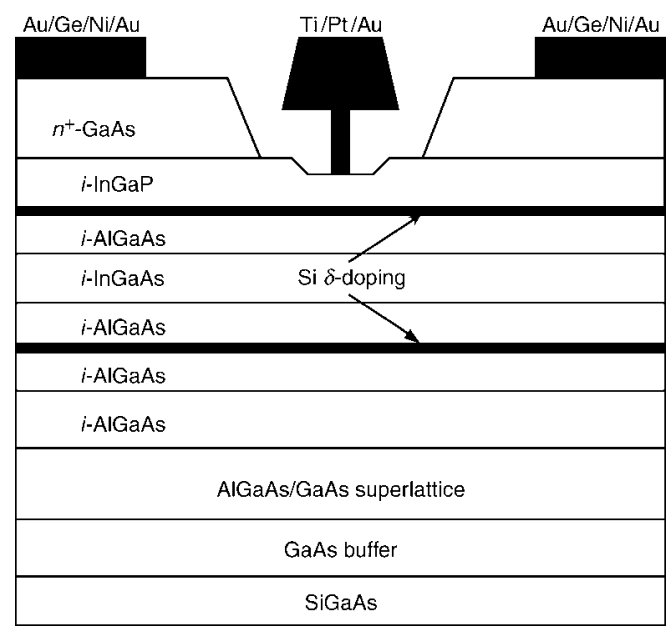

Fig. 1 Structure of InGaP/InGaAs PHEMT

Device manufacturing process: There are five major steps in the InGaP/InGaAs PHEMT process. These include definition of the device active region, ohmic metal deposition and annealing, wet chemical recess, gate formation by electron beam (EB) lithography and lift-off process and gold plating of airbridges for the interconnects. The mesa etch was achieved using $\mathrm{HCl} / \mathrm{H}_{2} \mathrm{O}$ solution etching for the InGaP layer [4] and $\mathrm{HF} / \mathrm{H}_{2} \mathrm{O}_{2} / \mathrm{H}_{2} \mathrm{O}$ solution for the other layers. The $\mathrm{AuGe} / \mathrm{Ni} / \mathrm{Au}$ was evaporated to form the ohmic contacts and was annealed at $340^{\circ} \mathrm{C}$ for $30 \mathrm{~s}$ by rapid thermal annealing. The gate recess was formed using a highly selective citric acid $/ \mathrm{H}_{2} \mathrm{O}_{2} / \mathrm{H}_{2} \mathrm{O}$ solution [5] for selectively removing the cap GaAs material and $\mathrm{HCl} / \mathrm{H}_{2} \mathrm{O}$ solution for etching the InGaP Schottky layer. The $\mathrm{Ti} / \mathrm{Pt} / \mathrm{Au}$ was then deposited for the Schottky gate by liftoff technique. The gate length for the device is $0.25 \mu \mathrm{m}$.

Results: Because of the use of InGaP layer and the AlGaAs spacer with dual delta doped structure, the device has very low leakage current, low-noise with very high IP3 that can be of great use for microwave applications.
The fabricated $0.25 \times 160 \mu \mathrm{m}^{2}$ PHEMT device shows saturation current of $243 \mathrm{~mA} / \mathrm{mm}$ and the high extrinsic transconductance is $414.2 \mathrm{mS} / \mathrm{mm}$ at $V_{d s}=1.5 \mathrm{~V}$. The device drain to gate breakdown voltage can reach up to $15.2 \mathrm{~V}$. The $160 \mu \mathrm{m}$ gate-width device has a noise figure of $0.59 \mathrm{~dB}$ with $11.7 \mathrm{~dB}$ associated gain at $12 \mathrm{GHz}$ and the $f_{t}$ and $f_{\max }$ are 80 and $190 \mathrm{GHz}$, respectively. The $0.25 \times 300 \mu \mathrm{m}^{2}$ PHEMT device shows high output 3 order intercept point (IP3) of $28.1 \mathrm{dBm}$ and the output power $1 \mathrm{~dB}$ compression $\left(\mathrm{OP}_{1 \mathrm{~dB}}\right)$ of $11.1 \mathrm{dBm}$ with gain $16.2 \mathrm{~dB}$ when DC bias at $V_{d s}=2.4 \mathrm{~V}, I_{d s}=28.6 \mathrm{~mA}$ at $6 \mathrm{GHz}$ as shown in Fig. 2. Compared with the conventional AlGaAs/ InGaAs PHEMT data, the $\mathrm{InGaP} / \mathrm{InGaAs}$ PHEMT developed has high $\Delta\left(\mathrm{IP}_{3}-\mathrm{OP}_{1 \mathrm{~dB}}\right)$ and high $\mathrm{IP} 3 / \mathrm{P}_{D C}$ ratio as shown in Table $1[6]$. Furthermore, gate leakage current of the device is very low. Fig. 3 shows the gate current against reverse gate-source voltage with different drain source, the gate current is $36 \mu \mathrm{A} / \mathrm{mm}$ at $V_{d s}=7 \mathrm{~V}, V_{g s}=-0.8 \mathrm{~V}$.

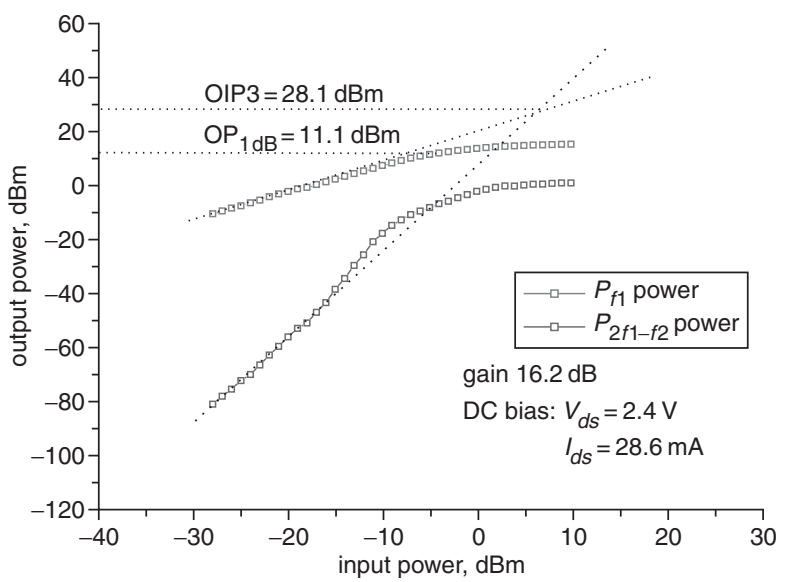

Fig. 2 Measured third-order products and fundamental power of $0.25 \times 300 \mu \mathrm{m}$ InGaP/InGaAs PHEMT

Table 1: Comparison of noise figure and IP3 with AlGaAs/ InGaAs PHEMT

\begin{tabular}{|c|c|c|c|c|c|c|}
\hline \multirow{2}{*}{$\begin{array}{c}\text { Device } \\
\text { type }\end{array}$} & \multirow{2}{*}{$\begin{array}{l}\mathrm{gm} \\
(\mathrm{mS} / \\
\mathrm{mm})\end{array}$} & \multirow{2}{*}{$\begin{array}{c}\text { Fmin }[\mathrm{dB}] \\
W g=160 \mu \mathrm{m} \\
\text { at } 6 \mathrm{GHz}\end{array}$} & \multicolumn{4}{|c|}{ IP3 with $W g=300 \mu \mathrm{m}$ at $6 \mathrm{GHz}$} \\
\hline & & & $\begin{array}{l}1 \mathrm{~dB} \text { comp } \\
\text { Pout }[\mathrm{dBm}]\end{array}$ & $\begin{array}{c}\text { IP3 } \\
{[\mathrm{dBm}]}\end{array}$ & $\begin{array}{c}\Delta\left(\mathrm{IP} 3-\mathrm{P}_{1 \mathrm{~dB}}\right) \\
{[\mathrm{dB}]}\end{array}$ & $\mathrm{IP} 3 / \mathrm{P}_{D C}$ \\
\hline $\begin{array}{l}\mathrm{InGaP} / \\
\text { InGaAs } \\
\text { double } \\
\text { delta- } \\
\text { doped }\end{array}$ & 414.2 & 0.4 & 11.1 & 28.1 & 17.0 & 9.4 \\
\hline $\begin{array}{c}\text { Double } \\
\text { delta- } \\
\text { doped } \\
\text { PHEMT }\end{array}$ & 432.0 & 0.6 & 12.7 & 23.0 & 10.3 & 1.6 \\
\hline
\end{tabular}

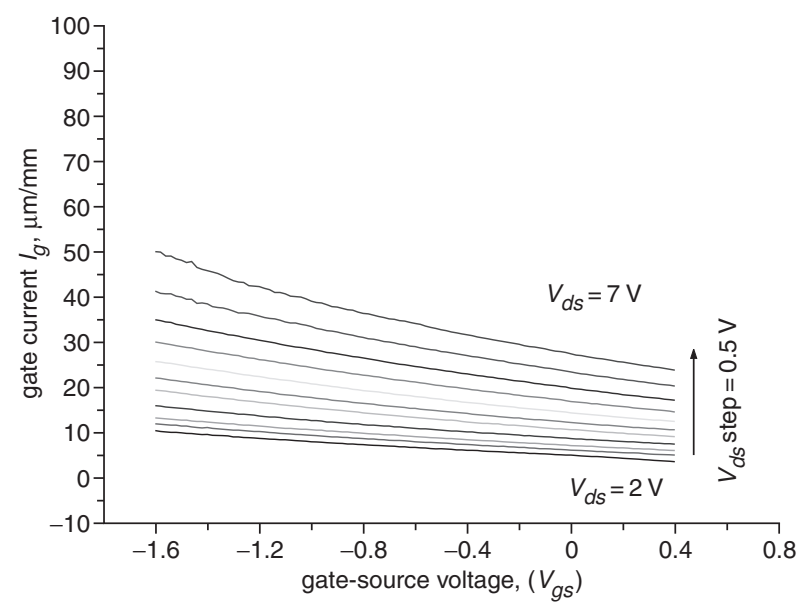

Fig. 3 InGaP/InGaAs PHEMT gate leakage current

Conclusion: An InGaP/InGaAs PHEMT with a very low noise figure, low third-order distortion, and low DC power consumption is developed. 
The outstanding performance of the device is attributed to the use of high bandgap InGaP as the Schottky layer so as to improve the noise figure and reduce the gate leakage current, along with the use of $\mathrm{AlGaAs}$ as the spacer to improve the electron mobility and the use of dual delta doped layers to improve the device linearity. The developed InGaP/InGaAs PHEMT with very low noise figure and leakage current and very high OIP3 is of great use for wireless communication applications.

Acknowledgments: The authors wish to thank the Ministry of Education and the National Science Council of the Republic of China for supporting this research under contract 92-EC-17-A-05-S1-020.

\section{(C) IEE 2004}

30 March 2004

Electronics Letters online no: 20040458

doi: 10.1049/el:20040458

Y.C. Lin, E.Y. Chang, G.J. Chen, H.M. Lee and D. Biswas (Department of Materials Science and Engineering, and Microelectronics and Information System Research Center, National Chiao Tung University, Hsinchu 300, Taiwan, Republic of China)

E-mail: edc@mail.nctu.edu.tw

G.W. Huang (National Nano Device Laboratories, Hsinchu 300, Taiwan, Republic of China)
Chun-Yen Chang (Department of Electronic Engineering, National Chiao Tung University, Hsinchu 300, Taiwan, Republic of China)

\section{References}

1 Wu, C.L., Wang, J.C., and Chang, C.S.: 'Super low noise InGaP gated PHEMT', IEEE GaAs Dig., 2001

2 Hur, K.Y., Hetzler, K.T., McTaggart, R.A., Vye, D.W., Lwmonias, P.J., and Hoke, W.E.: 'Ultralinear double pulse doped AlInAs/GaInAs/InP HEMTs', Electron. Lett., 1996, 32, (16)

3 Jkalainen, P.K., Witkowski, L.C., and Kao, Y.C.: 'Low-noise low DC power linear FET'. European Microwave Conf. Proc., 1992, Vol. 1, (22), pp. 570-575

4 Okamoto, Y., Matsunaga, K., Kuzuhara, M., and Kanamori, M.: 'Novel InGaP/AlGaAs/InGaAS heterojunction FET for X-Ku band power applications', IEEE MTT-S Int. Microw. Symp. Dig., 1997, 3, pp. 1191-1194

5 Zheng, H.Q., Ng, G.I., Zhang, Y.Q., Radhakrishnan, K., Lee, K.Y., Chee, P.Y., Tse, M.S., Weng, J.X., and Yoon, S.F.: 'High linearity, current drivability and $\mathrm{f}_{\max }$ using pseudomorphic GaAs double-heterojunction HEMT (DHHEMT)', Semicond. Electron., 1996, pp. 12-14

6 Chu, S.L.G., Huang, J., Struble, W., Jackson, G., Pan, N., Schindler, M.J., and Tajima, Y.: 'A highly linear MESFET', IEEE MTT-S Int. Microw. Symp. Dig., 1991, 2, pp. 725-728 